ENCYCIOPEDDE Encyclopédie berbère

BERBERE $\mathbf{3 3 |} \mathbf{2 0 1 2}$

33| N - Nektiberes

\title{
Nefza (Tribu)
}

Abderrahmane Khelifa

\section{OpenEdition}

Journals

Édition électronique

URL : https://journals.openedition.org/encyclopedieberbere/2702

DOI : 10.4000/encyclopedieberbere. 2702

ISSN : 2262-7197

\section{Éditeur}

Peeters Publishers

\section{Édition imprimée}

Date de publication : 4 octobre 2012

Pagination : 5381-5382

ISBN : 978-90-429-2640-0

ISSN : 1015-7344

Référence électronique

Abderrahmane Khelifa, « Nefza (Tribu) », Encyclopédie berbère [En ligne], 33 | 2012, document N31, mis en ligne le 23 novembre 2020, consulté le 17 février 2022. URL : http://journals.openedition.org/ encyclopedieberbere/2702; DOI : https://doi.org/10.4000/encyclopedieberbere.2702

Ce document a été généré automatiquement le 17 février 2022.

(c) Tous droits réservés 


\section{Nefza (Tribu)}

\section{Abderrahmane Khelifa}

1 Certaines sources médiévales arabes - c'est notamment le cas d'El-Idrîssî -, distinguent les Nefza des Nefzaoua* en attribuant à ces tribus des généalogies différentes ; ce que n'admettent pas en revanche Ibn Khaldoûn et d'El-Tidjânî. Yahia ibn Khaldoûn pour sa part affirme que D'ari, fils de Zadjih, fils de Madghis, est le père des Nefza.

2 Abû Omer Ibn Abd El-Berr dans son ouvrage intitulé Kitâb El-Tamhî̀ (Classification des généalogies), cité par Ibn Khaldoûn, évoque les tribus berbères qui quittèrent l'Egypte :

«Ils prirent pour habitation le territoire qui s'étend depuis la frontière de l'Egypte jusqu'à l'océan Vert (l'Atlantique) et la mer de l'Andalousie, en passant derrière Barca, et en se prolongeant jusqu'à la limite du Grand désert. De ce côté, ils se trouvèrent dans le voisinage immédiats des peuples noirs. Une de leurs familles, les Louata, occupa le territoire de Tripoli, et une branche, les Nefza, s'établit auprès de cette ville. De là, ils s'avancèrent jusqu'à Kairouan et passèrent en avant jusqu'à ce qu'ils parvinssent à Tahert, à Tanger, à Sigilmassa, et au Sous El-Aqça. Ces populations étaient des Sanhadja, des Ketama, des Dokkala, branche des Ouerglaoua, des Fetouaka, branche des Haskoura et des Meztaoua ».

Selon El-Nu'mân, l'Afrique du Nord reçut deux missionnaires chi'ites en 145H/762-63 dont l'un, El-Halwânî, s'installa dans le pays des Sumata, au nord-ouest de Qastiliya. Là, il convertit au chi isme des éléments appartenant aux Kutama, Nafza et Sumata. Plus tard, le Da'i (propagandiste) Abû Abd Allah El-Chi'i entreprit la conquête de l'Afrique du Nord par les armes. Il se dirigea vers Tébessa (295H/908), puis remonta vers Madjana, en attaquant les Malzuza, une fraction des Nefza au pied de la « Montagne des Meules » (Djabal El-Matahin), factuel Djebel Ouenza. Quand le pouvoir fatimide se mit en place, Bologguin, qui agissait pour leur compte, entreprit une expédition en 360H/971 contre les tribus du Hodna et du Zab. Il décima les Muzata, Houwwara et Nafza qui vivaient autour de Tobna, Msila, Baghaï et Biskra.

El-Bekrî en décrivant l'itinéraire qui mène de Kairouan à Mersa El-Zeïtoûna parle de Tidjis « entourée d'une muraille de pierre construite par les Roums, et possédant un faubourg, quelques bazars, un Djama' et un bain. On y trouve plusieurs familles berbères, appartenant aux tribus de Nefza, d'Ourghrouça, de Guezenaïa... De Tidjis, on se transporte à Constantine... ». Mais ces Nefza se retrouvent plus à l'ouest. Ainsi, en 
parlant de la fondation d'Oran (290H/902-903), El-Bekrî nous apprend que Mohammed Ibn Abi Aoun et Mohammed ibn Abdoun, les fondateurs de la ville, obtinrent l'accord des tribus Nefza et Mosguen qui occupaient le site. Il signale également qu'au début de la conquête musulmane, les Berbères Sanhadja et Ghomara de la région de Tamsaman et de Nokour se laissèrent convertir à l'Islam par Saleh ibn Mansour le Himyarite puis qu'ils abandonnèrent cette religion en prenant pour chef un nommé Daoud El-Rondi (natif de Ronda en Espagne). Cet homme appartenait à la tribu des Nefza. Ce qui fait penser que des éléments de cette tribu avaient émigré en Espagne au tout début de la conquête. D'après El-Bekrî, Idris II entreprit une expédition (en moharrem 197H/ septembre-octobre 812) contre la ville de Niffis, près de l'oued Dra', puis il affronta les Nefza et la ville de Tlemcen.

5 Bekr ibn Hammad, cité par El-Bekrî, composa un poème lors de l'attaque (338H/ 949-950) d'El-Bouri, fils de Mouça ibn Abi El-Afiya contre les Nefza dans la région de Tlemcen: «Demande aux Nefza comment il viola leur territoire jusqu'alors intact, pendant que leurs chevaux se vautraient sur l'herbe transpercés par ses lances flexibles ». Vers 362H/971-72, Bologguin ibn Ziri, écrasa les Mazata, les Houwwara et les Nefza

\section{BIBLIOGRAPHIE}

IBN ABD EL-HAKAM, Conquête de l'Afrique du Nord et de l'Espagne, traduction A. Gateau, Carbonel, Alger, 1947.

EL-BEKRÎ, Description de l'Afrique septentrionale, traduction de Slane, Paris, Geuthner, 1965.

EL-IDRîsSî, Le Maghreb au XII siècle, (VI siècle de l'Hégire), texte établi et traduit d'après Nuzhat ElMushtaq par M. Hadj Sadok, Alger, OPU, 1983.

IBN IDHARI EL-MERRAKUCHI, Kitâb El-Bayân El-Maghreb fi akhbâr El-Andalûs wa El-Maghrib, Leiden Brill. IBN KHALDOÛN A., Histoire des Berbères et des dynasties septentrionales de l'Afrique du Nord, 4 tomes, traduction de Slane, Geuthner, Paris, 1978.

IBN KHALDOÛN Y., Histoire des Béni Abd El-Ouad, rois de Tlemcen, traduction A. Bel, Fontana, Alger, 1903.

DACHRAOUI F., Le califat fatimide au Maghreb 296-362/909-973, histoire politique et institutions, Tunis, STD, 1981

POTIRON G., Tribus (Liste des tribus berbères), Mémoire de D.E.S., Université d'Alger, 1956.

INDEX

Mots-clés : Moyen Âge, Tribu, Tunisie 